\title{
Cultural Vacancy in Cultural Tourism English Translation and Its Countermeasures
}

\author{
Hong Liu \\ Yunnan Agricultural University, Kunming, Yunnan, 650201, China
}

\begin{abstract}
With the economic globalization and the progress of science and technology, people's living standards have been greatly improved and cultural tourism has gradually been an indispensable part of people at all ages. Because of customs, geography, values, religious beliefs and other different reasons, there are differences between the two cultures. In the process of translation, the phenomenon of cultural vacancies is very common. This requires that the translator must first understand the reasons for the emergence of cultural vacancies in Chinese-English translation, in addition to a strong cultural awareness of the two languages and cultural assumptions in order to find the right response.

Keywords: cultural vacancy, cultural tourism, English translation, countermeasures
\end{abstract}

\section{Introduction}

Tourism English translation plays an important role in the process of tourism activities, in order to solve the obstacles in the process of translation of tourism materials, first of all tourism English translation of the causes of obstacles indepth analysis. As translation activities are closely related to the cultural background, the causes of the obstacles are closely related to the cultural background.

Translation is not only the conversion between languages, but also between cultures. This is the basic nature of translation, because the direct language of translation is always closely linked with the culture. The close relationship 
between language and culture has determined the close relationship between translation and culture. From the perspective of intercultural communication, the original and translation are cultural products. The whole translation process is the process of cultural exchange. Translator "is dealing with individual words, and he is facing two large culture. Mary Snell-Hornby makes it clear that translation is a "cross-cultural activity." English and Chinese represent and reflect the Western culture and Chinese culture, is a typical representative of the world's culture. Due to geographical, social development and religious influence, the difference between the two cultures is very large, the emergence of cultural vacancies is common, but also to the Chinese-English translation has brought great challenges. This requires that the translator not only have a wide range of cultural awareness and cultural presupposition, but also have the correct concept of cultural translation.

\section{The cultural vacancy}

From the cultural point of view, the meaning of words is divided into linguistic and cultural significance. Some scholars will be referred to as "indicative" and "cultural connotation." It is the difficulty of translation and the foundation of translation to improve cultural awareness and establish cultural presuppositions so as to understand the cultural connotations of words.

The cultural connotation of the words does not correspond to the formation of the phenomenon of cultural gap between the languages and there has been a large number of "cultural vacancies". That is, English and Chinese can be found in the "directive" the same or similar words, but the cultural connotation of this or that there is no other. Two is completely vacant. That is, the English and Chinese languages cannot find the "instructive meaning" and "cultural connotation" the same or similar words.

Translation is a language activity, which involves two languages and a variety of knowledge. Translation is by no means a simple and mechanical transformation of the two languages. Mr. Lu Xun has proposed the translation standard of "faith and cis". He said: "All translation must take into account two: one of course seeks to be easy to understand, the two preserved the original posture." Mr. Lu Xun this translation of our translation is still a great lesson. The so-called "faith" refers to faithful to the original content and the original text of the complete and accurate expression of the translation of "Shun" is the correct word appropriate, fluent fluency, consistent with the target language habits, to avoid mechanically. The process of translation includes two important stages of understanding and expression. Only when the original text is correctly understood can the original text be expressed correctly and the original text cannot be separated from the context. However, in the process of translation, because the living environment between the source language and the target language is not the same, there will be a lack of corresponding cultural meaning in the target language, and cultural vacancies arise precisely because there are problems in the two important stages of translation. As an important cultural phenomenon in the 
intercultural translation, vacancy is caused by the difference of language and culture among nations. A language unique to a nation culture in another language and culture there is no corresponding phenomenon, so in the understanding and expression is prone to problems. Therefore, the translator must be proficient in two cultures, the phenomenon of cultural vacancies have knowledge and understanding in order to accurately express the original meaning.

Second, cultural vacancy phenomenon causes

\subsection{Regional differences}

Different living environment led to the political economy and cultural categories are not the same, so the use of vocabulary in life is certainly not the same category. In addition, different regions of the historical and cultural background is not the same, this series of differences will be formed in the region's unique cultural connotations.

\subsection{The values and ways of thinking are different}

Value is based on a certain person's sense of the senses to make the understanding (judgment or choice, that is, people identify things, distinguish between right and wrong of a thinking or orientation, which reflects people, things, things a certain value or role. Europe and the United States in the values and ways of thinking is very different from Western countries that people are born guilty, while China believes that "the beginning of human nature is good."

\subsection{Religious beliefs are different}

Religious belief is a kind of ideology, it is a kind of spiritual custom, it is extremely complex, and mankind's production, life, work and study and so on each aspect have the inexhaustible contact. Religious groups of the sacred object of their faith are a conversion of wholeheartedness, its conviction firmly. Each nation's beliefs are different and these differences will affect people's values, behavioural thinking and language habits.

\subsection{Different customs}

Custom is a kind of behaviour pattern or norm which common people abide by in different social areas. The difference of behaviour norms caused by different natural conditions is called "wind", but different behaviour rules caused by social and cultural differences. "Baili different winds, thousands of miles of different customs" is appropriately reflects the customs of different local characteristics, these differences will lead to national thinking and speech between the differences. 


\section{The objective reasons for the barriers of tourism English translation}

Tourism English translation plays an important role in the process of tourism activities, in order to solve the obstacles in the process of translation of tourism materials, first of all tourism English translation of the causes of obstacles indepth analysis. As translation activities are closely related to the cultural background, the causes of the obstacles are closely related to the cultural background. There are two reasons for the obstacles in tourism English translation:

\subsection{The differences between Chinese and English expressions}

Chinese language style and English language style is very different, the Chinese emphasis on meaning, and the emphasis on English combined type. Chinese tourism propaganda materials diction, the format used to match, parallel, it is magnificent, it is able to attract the attention of tourists. While writing tourism promotional materials in English, pay more attention to the sentence structure, the use of rhetoric is not so gorgeous, the format is not very neat. English expression is more focused on the actual amount of information conveyed by the amount of useful information. In the process of Chinese-English translation, if the translation in strict accordance with the original word for word, it is too longwinded, not in line with the expression of English habits.

\subsection{The differences between Chinese and English traditions and customs}

Because of the difference of life background, Chinese and Westerners have the opposite understanding of the same thing. Bats, for example, are synonymous with good fortune in China, but in the West, bats represent vampires, with evil connotations. Therefore, when the introduction of Lijiang River in Guilin, bat Mountain to tourists, we must explain the implied meaning behind the bat more blessings, or when foreign tourists hear the name of the mountain, because the traditional customs of the differences, the mountain Imagine a terrible, even refused to visit. Therefore, in the face of such cultural differences caused by traditional customs issues, we must introduce the Chinese cultural background to visitors, so as not to cause unnecessary misunderstanding.

\section{The subjective reasons for the tourism English translation obstacles}

The above analysis is the objective reasons leading to the obstacles in the process of tourism English translation. The causes of things are usually divided into two parts: subjective and objective. The subjective causes of translation barriers are as follows: 
It cannot be a thorough understanding of the original language and cultural background, the translation is not appropriate situation. Tourism English translation contains more content, in addition to all aspects of daily life, the most important thing is the translation of the tour guide, and the main tour guide word, the main tourist guide, Is the description of the cultural aspects of the content of the traditional Chinese culture, material, institutional and spiritual as the main form, encompassing the ancient Chinese architecture, religion, thought, diet and other specific aspects. The connotation of Chinese culture is profound and profound, so it is necessary to translate these long-term connotations and correspondingly need higher ability of the conversion between the two cultures. If the translator's understanding of the original text is not thorough enough, it is difficult to imagine the translator can successfully translated the original text.

If the translator does not have a thorough understanding of the original content in the process of translation, the translation will not be successful. In particular, tourism knowledge involves a wide range of aspects, so a translator must fully understand the original text and understand the original relevant cultural background and knowledge, so that translated works can have a certain level.

The translation can correctly understand the original, but does not meet the target language expression. In the translation process of tourism English, this phenomenon usually occurs, although the translator can correctly understand the original, but the translation of the target language allows foreigners to feel very confused. Although the translators can respect the cultural characteristics of the original text, the translator does not conform to the characteristics of the target language because of the limitation of the translator's ability to translate. This kind of text contains some vocabularies that are unique to Chinese language and culture. Translation is not a successful translation, because the translator is not able to close to the target language of the language habit of translation. In other words, it is only close to the original cultural background, while ignoring the cultural characteristics of the target language expression habits of translation is not a good translation. For Chinese consumers to see the dish name can not only guess the raw materials of dishes, but also know that the name of the Western $\mathrm{Cu}$ Xiang Yu Xiang $\mathrm{Yu}$ in the dead end is the story between the concubine Yuji separated, not only that, consumers But also to understand the homonym of this clever rhetoric means to add luster to this dish name.

English and Chinese are two different languages in the humanities, customs and historical and cultural backgrounds have their own distinct characteristics, it can be said in terms of cultural differences in the two languages there are very different. This requires the translator to have a good understanding of the cultural differences between the two languages during the process of translating the materials, otherwise the mismatch in the translation process will easily appear in the translation process, English translation of the two languages on the bridge, there is no real translation into the target language, not really into the English culture. In the actual process of tourism English translation, there are many incomplete translations. 


\section{The Translation Strategies}

Some of the cultural connotations in Chinese cannot be found in the corresponding English words, and that is completely vacant phenomenon, it is appropriate to use transliteration or transliteration filling method. Many of the words that have been translated in this way have been accepted into English as a foreign word in English. Donnson Chen will be in English from the Chinese loan words categorically list out two hundred. From this we can see the vitality of transliteration.

Some of the cultural connotations in Chinese can be found in English with the same or similar corresponding meaning of "indicative meaning" and that is part of the phenomenon of vacancy, it is appropriate to use translation or semantic regeneration translation. From the Chinese ancient literature, philosophical thought or Buddhist culture of the unique things also should be translated by the loan or semantic translation into English in China.

\section{Conclusion}

In order to adapt to the objective requirements of cultural exchange, the cultural vacancy should be translated into "Chinese English" by means of alienation and cultural equality. But in practice, some Chinese cultural information will be lost in the process of symbol conversion; and some Chinese cultural information is achieved through the phonetic or semantic pun of Chinese characters. Such information in the symbol conversion process may be achieved through image conversion. It can be seen that the translation of cultural vacancies is worthy of further study.

\section{References}

[1] Wang Qing. The translational cultural differences and corresponding translation principles in tourism English translation. 55(12), pp.68-70, 2011

[2] Ding Xin. Research on the Causes and Countermeasures of Tourism English Translation Obstacles 8 (5), pp.87- 91, 20013

[3] Chen Hui. Analysis of tourism English translation methods. Journal of Suzhou Education Institute 12(10), pp. 18- 20, 2012

[4] Xiao Le. Discussion on the creativity in Tourism English translation. Foreign Language. 9(6), pp.58-61, 2011

[5] A Study on the Translation Strategies of tourism English from the Perspective of Cross - culture. Foreign Language Research 8(4), pp.85-87, 2014 